\title{
Mudança de Práticas: O Fazer Obstétrico na Grande Vitória/ES
}

\author{
Ana Carolina Júlio \\ Universidade Federal do Espírito Santo - Brasil \\ carol.juliosilva@gmail.com
}

\section{Resumo}

O objetivo deste trabalho é analisar como a organização do fazer obstétrico motiva os praticantes a optar pelo parto humanizado, contribuindo para a mudança dessa prática. A pesquisa foi conduzida por meio da observação, empregando a onto-epistemologia da prática segundo Theodore Schatzki e a análise temática dos dados. Os resultados apontam que diferentes entendimentos acerca do corpo levam à reprodução das práticas obstétricas ou ao esforço em prol da sua mudança. Quando o corpo da mulher é tido enquanto um objeto (sendo a mulher uma mente que detém um corpo), a gravidez é um problema a ser resolvido. Por outro lado, quando esse passa a ser um "corpo-pessoa", não é possível desassociá-lo da mulher. Consequentemente, a gravidez deixa de ser um problema, tornando-se um processo natural e fisiológico que deve ser respeitado, e não solucionado o mais rápido possível. Este trabalho contribui com o campo ao analisar como a mobilização das práticas se altera ao longo do tempo. Além disso, o estudo da obstetrícia revela a centralidade do corpo na performance dessa prática social. Afinal, é o corpo da mulher que entra em trabalho de parto, que dá à luz e que, infelizmente, ainda sofre violência obstétrica. Enfim, é esse o "veículo" que transporta as práticas.

Palavras-chave: Estudos Baseados em Prática (EBP), organizing, Theodore Schatzki, práticas obstétricas 


\title{
Changing Practices: Obstetric and Childbirth Practices in Vitória/ES
}

\author{
Ana Carolina Júlio \\ Universidade Federal do Espírito Santo - Brasil \\ carol.juliosilva@gmail.com
}

\begin{abstract}
This paper analyzes how the organization of obstetrical practice motivates a community to choose for humanized childbirth, contributing to the change of this social practice. The research was conducted through observation, employing Theodore Schatzki's practice ontoepistemology and thematic analysis of the data. The results point out that different understandings about the body lead to the reproduction of obstetrical practices or to the effort for their change. When a woman's body is taken as an object (woman is a mind that holds a body), pregnancy is a problem to be solved. On the other hand, when it becomes a "body-person," it is not possible to disassociate it from the woman. Consequently, pregnancy ceases to be a problem, making it a natural and physiological process that must be respected, and not solved as quickly as possible. This work contributes to the field by analyzing how the mobilization of practices changes over time. In addition, the study of obstetrics reveals the centrality of the body in the performance of this practice. After all, it is the body of the woman who goes into labor, who gives birth and who, unfortunately, still suffers from obstetric violence. In short, the body is the "vehicle" that transports practices.
\end{abstract}

Key Words: Practice Based Studies (PBS), Organizing, Theodore Schatzki, obstetric practices 
Segundo o inquérito nacional "Nascer no Brasil”, conduzido pela Fundação Oswaldo Cruz (Fiocruz) e pelo Ministério da Saúde, 52\% dos partos realizados no país são cesarianas. No setor privado, a proporção de partos cirúrgicos chega a 88\%, enquanto que no público o percentual é de 46\% (Fundação Oswaldo Cruz (Fiocruz), 2016). Além disso, de acordo com a declaração da Organização Mundial da Saúde (OMS) sobre as taxas de cesária, divulgada em 2015, somos o país com o maior percentual de partos cirúrgicos do mundo (World Health Organization (WHO), 2016; Betran, Torloni, Zhang, \& Gülmezoglu, 2015).

A recomendação da OMS é de que as cesarianas não excedam 15\% do total de partos, uma vez que os riscos das elevadas taxas de partos cirúrgicos para a saúde da mãe e do bebê (que pode nascer prematuro devido ao agendamento do parto, por exemplo) já foram evidenciados na literatura científica (Fiocruz, 2016). Todavia, o parto no Brasil é visto majoritariamente enquanto um evento médico tecnocrático (Davis-Floyd \& John, 1998), estando centrado no obstetra. Consequentemente, a gestante/parturiente é apenas mais uma paciente - e não a protagonista do processo - e a assistência ao parto é intervencionista, mesmo quando não há motivos clínicos para tais intervenções (Patah \& Malik, 2011; Georges \& Davis-Floyd, 2016).

Estudos recentes revelam que questões afetivas - como o medo de sentir dor durante o parto; a comodidade (para a gestante, a família e os profissionais da saúde) de poder marcar a cirurgia; a influência do obstetra e a visão de que a cesariana é a forma mais tecnológica e, portanto, a mais segura de parir - podem nos ajudar a dar explicações para essa proporção de partos cirúrgicos no Brasil (Fiocruz, 2016; Domingues et al., 2014; Georges \& DavisFloyd, 2016).

Aliás, desde de a década de 1990, estudos internacionais como o de Wiegers, Van Der Zee, Kerssens \& Keirse (1998) evidenciavam que o medo da dor e de possíveis complicações durante o parto influenciam a decisão em relação ao local de nascimento do bebê (que na Holanda - local onde o estudo foi realizado - ocorre majoritariamente em casa, mas também nas maternidades); o que ilustra que questões afetivas como o medo orientam as práticas obstétricas.

Segundo Domingues et al. (2014, p. S112), “[...] a gravidez é um momento único na vida de uma mulher. Como um rito de passagem para a maternidade, é carregado de mitos e simbolismos”. Dessa forma, a preferência pelo tipo de parto não é meramente determinada por fatores clínicos, sendo influenciada por fatores culturais e socioeconômicos (Domingues et al., 2014) - como a percepção que se tem sobre a (in)capacidade de o corpo da mulher dar 
a luz, por exemplo. Isso faz com que a decisão pelo tipo de parto (normal ou cirúrgico) vá além de uma escolha meramente racional (Davis-Floyd \& John, 1998).

No campo dos Estudos Organizacionais (EOs), mais especificamente nos Estudos Baseados em Prática (EBP), algumas práticas médicas, como o uso da telemedicina para monitorar cardiopatas, a reprodução assistida e o auto monitoramento de diabéticos já foram estudadas (Ver Nicolini, 2013; Gherardi \& Perrotta, 2011; Bruni \& Rizzi, 2013). No contexto brasileiro, quando se problematizam as práticas médicas, as práticas obstétricas se revelam como uma temática a ser explorada. Afinal, somos o país com o maior percentual de partos cirúrgicos do mundo (WHO, 2016; Betran et al., 2015).

Todavia, apesar de a maioria dos nascimentos no Brasil se dar pela via cirúrgica, é crescente o número de gestantes, pais e profissionais da saúde (obstetras e doulas ${ }^{1}$, por exemplo) que, baseando-se em evidências cientificas, optam pelo parto humanizado² $\mathrm{e}$ realizam um esforço incremental em prol da mudança das práticas obstétricas (Ver Diniz, 2005). Dessa forma, estudo da obstetrícia brasileira pode ajudar a compreender como a mobilização das práticas se altera ao longo do tempo. Apesar da relevância e do impacto social, as práticas obstétricas ainda não foram muito exploradas pelos pesquisadores organizacionais brasileiros.

Diante disso, o objetivo desta pesquisa é: analisar como a organização do fazer obstétrico motiva determinados praticantes (gestantes/parturientes, pais, obstetras e doulas que performam essa prática em hospitais/maternidades e fora deles) a optar pelo parto humanizado, contribuindo, assim, para a mudança das práticas obstétricas.

As práticas sociais (enquanto ditos e feitos) estão para além de um padrão de ação, abarcando atividades que estão em constante transformação. As práticas são diversas e variáveis, sendo (re)combinadas e alteradas de acordo com seu uso (T. R. Schatzki, 2002, 2012); afinal, a realidade social é complexa e múltipla, havendo uma variedade de ordens, lógicas e discursos que, assim como as práticas, podem se sobrepor e coexistir (Mol, 2002;

\footnotetext{
${ }^{1}$ Mulheres que dão suporte físico e emocional a outras mulheres durante a gestação, o parto e o pós-parto. Durante o trabalho de parto, ajudam a parturiente a encontrar posições confortáveis, propondo medidas naturais e não farmacológicas que aliviam as dores (respiração, banho/compressa quentes e massagens, por exemplo). A OMS e o Ministério da Saúde reconhecem e recomendam o apoio das doulas às gestantes/parturientes (Universidade de São Paulo (USP), 2016).

${ }^{2}$ Por parto humanizado entende-se aquele cuja assistência baseia-se no respeito à liberdade e à fisiologia da mulher, assim como em evidências científicas recentes (e não no costume médico). Nessa forma de assistência, as parturientes têm o direito de conhecer e até mesmo decidir sobre os procedimentos aos quais serão submetidas.! Assim, busca-se inverter a lógica que avalia o corpo feminino como incapaz de parir, o parto normal como arcaico e o obstetra enquanto o protagonista do processo (Diniz, 2005; WHO, 2016).
} 
Mol \& Law, 2002; T. R. Schatzki, 2002). Dessa forma, este trabalho pode contribuir com o campo por buscar analisar como a mobilização das práticas se altera ao longo do tempo; o que nos ajuda a apreender não somente o dinamismo das práticas obstétricas, mas também de toda e qualquer prática.

Em relação ao referencial teórico adotado, para Schatzki e Reckwitz, teóricos dos EBP, toda prática está organizada em torno de uma dinâmica teleoafetiva. Ou seja, afetos, sentimentos, emoções e humores são dimensões básicas, constitutivas e fundadoras da vida social, assumindo um papel ativo na constituição dos processos organizativos e da realidade social, podendo orientar o que as pessoas fazem (T. R. Schatzki, 2002; Reckwitz, 2012). Quanto à análise e interpretação dos dados, emprego a análise temática (Ryan \& Bernard, 2003); assim como o procedimento de codificação de dados propostos por Corbin e Strauss (1990).

Saliento que o uso da expressão "práticas obstétricas” (e não "práticas médicas”) é intencional, uma vez que a medicina baseada em evidencias nos mostra que a gestante deveria ser o centro de um modelo humanizado de atenção ao parto (WHO, 2016; Betran et al., 2015; Fiocruz, 2016; Domingues et al., 2014). A expressão “práticas médicas” focaliza o obstetra enquanto praticante, marginalizando o fato de as práticas sociais serem performadas por uma ampla gama de atores. Entendo que os EBP têm potencial para ir além dessa limitação e que críticas já foram tecidas em relação aos estudos cujo foco analítico está reduzido aos praticantes centrais, tais como gerentes de alto escalão, ou estrategistas (Ver Mantere, 2005; Carter, Clegg \& Kornberger, 2010).

Dessa forma, considero que as “práticas obstétricas” estão para além do fazer médico, englobando tanto procedimentos técnicos (os exames de pré-natal; o uso de ocitocina; a analgesia farmacológica; a episiotomia; a cesária, etc.) quanto práticas mais humanizadas e não necessariamente médicas (a busca das gestantes por informações baseadas em evidências; o suporte da família e da doula durante a gestação, parto e pós-parto; a analgesia não farmacológica; o parto natural, etc.).

Por fim, após esta breve introdução, exponho o referencial do trabalho, discutindo a onto-epistemologia da prática segundo Schatzki. Na sequência, apresento e analiso os resultados que emergiram da análise temática. Por fim, teço minhas considerações finais, sem pretender esgotar a discussão.

\section{Onto-epistemologia da Prática Segundo Schatzki}


O enfoque filosófico sobre o papel constitutivo das práticas na (re)produção da realidade social é uma das maneiras de se estudar os fenômenos sociais/organizacionais. Heidegger (assim como Wittgenstein) são bases filosóficas contemporâneas influentes das abordagens da prática e de autores como Foucault, Butler, Latour, Schatzki, etc. (Nicolini, 2013; Feldman \& Orlikowski, 2011; Reckwitz, 2002), apesar de suas ideias ainda terem sido pouco exploradas pelos cientistas sociais/organizacionais.

Dessa forma, "dar um passo atrás" e problematizar nossa compreensão acerca da ação e da ordem social é uma forma de buscar compreender melhor nossas lentes de análise e, consequentemente, nossos "objetos" de estudo (ou seja, os fenômenos sociais/organizacionais). É justamente isso o que faz T. R. Schatzki (2006); uma vez que, por meio da "primazia da prática" heideggeriana, o autor questiona o status dos fenômenos que estuda (Nicolini, 2013; Feldman \& Orlikowski, 2011; Reckwitz, 2002). De acordo com a ontoepistemologia da prática segundo Schatzki, as práticas são o principal elemento constitutivo da vida social, o bloco fundador do mundo no qual estamos "desde sempre" imbricados. Consequentemente, a prática é compreendida como o ponto de partida para qualquer investigação ou entendimento das relações humanas (Reckwitz, 2002; Nicolini, 2013; Júlio, 2016).

O autor conceitua a prática para além da ação rotinizada, para além de um padrão de ação; referindo-se a um nexo de atividades humanas organizadas e de arranjos materiais, a um conjunto de ações corporais de fazer e dizer. Os arranjos suportam as práticas, o que inclui humanos e não-humanos, o corpo dos indivíduos e eventuais extensões desse corpo, por exemplo (T. R. Schatzki, 2002, 2012).

Para Heidegger (2005), uma das bases filosóficas de Schatzki, os arranjos materiais (instrumentos) têm potencial para revelar múltiplas finalidades (telos). Todavia, nós (enquanto praticantes) tendemos a atribuir uma "pertinência primeira", uma finalidade previamente arbitrada a esses arranjos, o que pode ter um efeito normativo sobre o curso de nossas ações. Diante disso, os corpos, enquanto arranjos, também revelam essa "instrumentalidade", essa finalidade primeira. É justamente por isso que há uma "referência”, um "para que serve" dos corpos.

Vale ressaltar que essa finalidade se revela em uma conjuntura ("mundo circundante”),

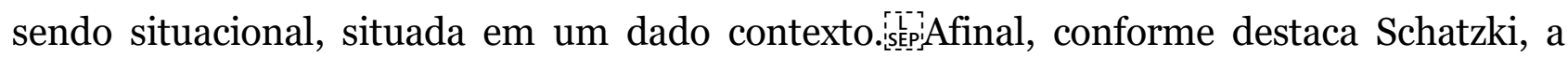
prática é situada no tempo e no espaço, em um dado contexto histórico e social (espaço de 
inteligibilidade ou clearing); uma vez que a temporalidade das práticas é teológica, sendo passado, presente e futuro recursivos. É justamente essa recursividade que permite resgatar a historicidade dos processos organizativos; o que evidencia que os fenômenos sociais são parte desse contexto histórico e social (T. R. Schatzki, 2005; 2006; Júlio, 2016).

Schatzki também salienta que não há fronteiras rígidas separando as práticas, uma vez que as mesmas são abertas e melhor compreendidas através de seu dinamismo e movimento, abarcando atividades (ir)regulares, únicas e que estão em constante mudança. As práticas podem se sobrepor. Ou seja, um mesmo fazer ou dizer (enquanto atividades) pode pertencer a mais de uma prática (T. R. Schatzki, 2002, 2012). Tais mudanças se dão, ainda, de modo gradual e incremental: alteram-se alguns dos componentes da malha, enquanto outros persistem inalterados; sendo a agência humana a fonte primária de mudança de qualquer nexo de práticas e arranjos (T. R. Schatzki, 2002).

\section{Como as Práticas se Organizam}

As práticas não são apenas performances corporais rotineiras, mas também, e ao mesmo tempo, conjuntos de atividades mentais. Assim, a prática implica, necessariamente, determinadas maneiras de compreender o mundo, de desejar algo, de saber o que e como fazer (Reckwitz, 2002). Nesse contexto, a organização das práticas se dá em torno de três elementos: entendimentos, regras e teleoafetividades (T. R. Schatzki, 2002, 2005). São esses elementos que organizam as práticas, que fazem com que determinados ditos e feitos estejam reunidos sob uma mesma atividade humana, em torno de uma mesma prática social (Santos \& Silveira, 2015).

O entendimento da prática refere-se ao know-how, à habilidade de um praticante realizar determinadas atividades, assim como a capacidade de esse praticante entender o significado de uma prática. O entendimento da prática é socialmente compartilhado pelos praticantes, que concordam (têm o mesmo julgamento), pelo menos tacitamente, em relação ao que faz ou não sentido. Entendimentos e know-how são propriedades das práticas e não dos praticantes. Durante sua socialização, os indivíduos aprendem como se tornar praticantes, adquirindo e incorporando microversões dos elementos que organizam as atividades nas quais encontram-se imbricados (T. R. Schatzki, 2002, 2005; Reckwitz, 2002).

As regras dizem respeito a normas, princípios, instruções, critérios de decisão ou convenções sociais que são formulados e prescritos (de forma mais ou menos explícita, ou 
até mesmo implícita), sendo socialmente aceitas e compartilhadas. Todavia, ressalta-se que as regras não estão, necessariamente, vinculadas a mecanismos de poder e autoridade, ou a sanções. As regras são performadas, uma vez que seu efeito normativo é praticado, e não prédeterminado. Dessa forma, nenhuma ação deve ser tida, pelo menos a priori, como determinada por uma regra (T. R. Schatzki, 2002, 2005).

A teleoafetividade refere-se a uma complexa combinação de propósitos (telos) e afetos, ao senso de propósito (fins e meios para se alcançar esse fim) e aos humores e emoções que os indivíduos sentem ao se engajarem em uma prática. Os teleoafetos também são aprendidos pelos indivíduos durante sua socialização, sendo reforçados pela repetição dessas práticas e por sanções explícitas ou tácitas (Nicolini, 2013). Assim, a teleoafetividade que organiza uma determinada prática é socialmente compartilhada, sendo aceita e considerada legítima no contexto histórico e social dessa prática (T. R. Schatzki, 2002, 2005; Santos \& Silveira, 2015).

Conforme mencionado, os elementos que organizam as práticas (entendimentos, regras e teleoafetividades) são incorporados pelos praticantes durante seu processo de socialização. É dessa forma que os entendimentos se transformam em know-how, as regras em crenças e as teleoafetividades em desejos. Todavia, tais elementos são incorporados de formas distintas por diferentes praticantes, sendo (re)combinados de diversas maneiras, uma vez que os indivíduos não são idênticos (possuem socialização, experiências, inteligências, sensibilidade, capacidade de observação, poder e status distintos). Assim, cada praticante carrega consigo uma microversão dos elementos que organizam as práticas das quais fazem parte (T. R. Schatzki, 2002, 2005).

Por fim, T. R. Schatzki (2002, 2006) e T. Schatzki (2013) salientam que as práticas permanecem ou se alteram ao longo do tempo devido à persistência/mudança dos elementos que as suportam, ou seja, devido à performance das atividades humanas; aos elementos regras, entendimentos e teleoafetos que organizam as práticas; e aos arranjos materiais. Segundo o autor, a dissolução de uma determinada prática implica, frequentemente, no lento desenvolvimento de um novo emaranhado de práticas (de regras, entendimentos, teleoafetos e arranjos); o que abarca não apenas o processo de dissolução, mas também (e ao mesmo tempo) a emergência de novas práticas (T. Schatzki, 2013).

Esse duplo processo de “dissolução-emergência” pode acontecer quando novos meios e fins (ou seja, novas teleoafetividades) passam a organizar uma prática, o que também pode transformar os entendimentos práticos dos indivíduos que performam essa prática, afinal, a 
motivação e o propósito da ação também são alterados (T. Schatzki, 2013). A mudança dos entendimentos práticos que organizam uma prática nascente resulta em novas (re)ações (fazeres e dizeres) emergentes e não refletidas (nonpropositional bodily abilities) dos praticantes; ou seja, na mudança das performances corporais desses praticantes diante de novos eventos e circunstâncias (T. R. Schatzki, 2002, 2012; T. Schatzki, 2013; Nicolini, 2013). No caso das práticas obstétricas, a mudança da performance corporal pode ser evidenciada quando um profissional da saúde se refere espontaneamente a uma mulher usando o termo "gestante" ou "parturiente", e não mais o termo "paciente"; conferindo-lhe poder de agência.

\section{Coletando os Dados}

Apesar de não estar centrada em uma organização hospitalar, as práticas observadas neste estudo perpassaram um hospital universitário da cidade de Vitória. Afinal, o acontecimento (T. R. Schatzki, 2006) de um fenômeno social é multissituado (Marcus, 1995), podendo se desdobrar em múltiplos lugares, não se concentrando em um único espaço social. Por conta disso, para compreender e analisar o processo organizativo (organizing), o pesquisador deve vivenciar seu acontecimento na medida em que ele se desdobra, "seguindo" a rede de práticas que (re)constitui a organização (T. R. Schatzki, 2006; Czarniawska, 2013).

Diante disso, a observação - com descrição densa das notas registradas em diários de campo - foi a principal técnica de coleta de dados deste estudo (Rosen, 1991). A pesquisa de campo começou no final de agosto de 2016, com término em meados de novembro do mesmo ano. Conforme destaca Spradley (1979), os pesquisadores coletam a maior parte de seus dados por meio da observação participante e de conversas casuais e informais. É dessa forma que se estabelece diálogos mais fluidos com os sujeitos de pesquisa, conduzindo uma conversação amigável, ao mesmo tempo em que se introduz questões caras a sua pesquisa.

Realizei 12 observações, totalizando cerca de 50 horas de trabalho, sendo a duração média de cada observação de 4 horas. A investigação aconteceu em diferentes contextos: na assembleia legislativa do ES (onde uma audiência pública sobre violência obstétrica ocorreu), em um estúdio de pilates (onde gestantes e mães se exercitam), em uma universidade federal (onde um grupo de doulas e gestantes se reúne), em um shopping da Grande Vitória (onde aconteceu um encontro de gestantes, obstetras e doulas), e na 
maternidade de um hospital universitário (onde gestantes são assistidas e partos realizados).

Durante meu trabalho como pesquisadora, busquei observar e registrar densamente em meu diário de campo comportamentos, opiniões e comentários dos "nativos" (Angrosimo, 2007), sendo meu intuito compreender o ponto de vista, a visão de mundo (Malinowski, 1978), a lógica social e contextual que organiza o grupo estudado (Boas, 2004). Minha última observação aconteceu no dia 14 de novembro, quando acompanhei o plantão de um obstetra (que se tornou meu informante) na maternidade de um hospital universitário.

\section{Acessando o Campo}

O acesso ao campo se deu por meio de uma amiga (também pesquisadora) que passou pela experiência do parto natural humanizado e foi assistida por um obstetra e uma doula durante o nascimento do seu primeiro filho. Meu primeiro contato com o campo aconteceu no dia 22 de agosto, quando estive com essa amiga que se transformou em um dos meus informantes. Após essa primeira entrevista exploratória, fui convidada por uma doula a participar de uma audiência pública sobre violência obstétrica que ocorreria na assembleia legislativa do ES, no dia 23 de agosto. Foi justamente nessa audiência que conheci muitos dos sujeitos que passei a seguir.

Nas primeiras duas semanas de trabalho, conheci doulas, gestantes e mães. Até então, a prática obstétrica se revelava para mim por meio de gestantes e pais que sonhavam em ter um parto natural humanizado, assim como através de doulas e mães que, muitas vezes, tinham sofrido violência obstétrica e experienciado um parto cheio de intervenções desnecessárias em seus corpos e, até mesmo, nos corpos de seus bebês; o que as motivava a trabalhar em prol da humanização.

Ao mesmo tempo em que passei a observar as reuniões quinzenais desse grupo, busquei contatar alguns obstetras reconhecidos no estado por trabalharem em prol do parto humanizado. No dia 12 de setembro, um desses obstetras, que além de atender em seu consultório particular é médico do hospital universitário, respondeu, via facebook, uma das mensagens que eu havia enviado. No dia 22 do mesmo mês, agendamos uma entrevista exploratória e nos conhecemos pessoalmente. A partir desse contato, esse obstetra se transformou em um dos meus informantes, facilitando meu acesso ao hospital universitário, 
o que fez com que o campo passasse a se revelar de outra forma para mim.

Sendo as práticas situadas no tempo e no espaço, ou seja, em um dado contexto (T. R. Schatzki, 2005; 2006); saliento que a maioria dos sujeitos/praticantes que passei a seguir fazem parte de grupos sociais mais abastados e de alta escolaridade (podendo arcar com os custos de uma doula e/ou de um obstetra particular, por exemplo). Consequentemente, o fazer obstétrico aqui em análise está situado nesse contexto socioeconômico, sendo organizado em torno dessa lógica social.

Apesar de o campo ser novo e "estranho", por questões pessoais, me identifico fortemente com a temática "práticas obstétricas". Dessa forma, e também por considerar que não há uma divisão estanque entre observação participante e não participante, sendo a dicotomia atribuída aos diferentes mecanismos de observação, na verdade, um continuum (Scott, 1972), entendo que, em alguns momentos, minha identidade como pesquisadora já começa a se mesclar a minha identidade enquanto participante/praticante dessas práticas. Enquanto pesquisadora, estou mergulhando "de cabeça" no cotidiano desse grupo social, buscando apreender o maior número possível de perspectivas, aculturando-me, assimilando a lógica que organiza o universo cultural investigado (Yanow, 2012).

Conforme destaca Yanow (2012), a observação requer que o pesquisador ganhe a confiança das pessoas do grupo, aproximando-se com sensibilidade, empatia e flexibilidade, reconhecendo o momento de perguntar e de calar. Justamente por isso fui bastante parcimoniosa em relação ao uso do meu caderno de campo; afinal, pude perceber que minhas anotações causavam grande estranhamento, já que a temática "práticas obstétricas" abarca um momento muito pessoal e íntimo das gestantes e de seus companheiros. Dessa forma, antes de iniciar meu trabalho de observação, procurei me apresentar enquanto pesquisadora, e anotar o mínimo possível. Assim que as observações terminavam, fazia anotações gerais do que presenciei, expandindo-as densamente no mesmo dia, diretamente para o Word.

\section{Analisando os Dados}

Neste trabalho, em relação à análise e interpretação dos dados, emprego a análise temática (Ryan \& Bernard, 2003); assim como o procedimento de codificação de dados propostos por Corbin e Strauss (1990). Minha codificação inicial foi aberta, sendo essa etapa um processo interpretativo no qual o pesquisador faz comparações e busca semelhanças e 
diferenças no conteúdo do corpus (Corbin \& Strauss, 1990), no conteúdo das notas de campo expandidas em diários, por exemplo. Logo em seguida, iniciei a codificação axial, buscando estabelecer relações entre as categorias. Diante disso, apresento, por meio das categorias e subcategorias, as atividades e práticas obstétricas em análise.

\begin{tabular}{|c|c|c|}
\hline \multirow{3}{*}{$\begin{array}{l}0 \\
0 \\
0 \\
0 \\
0 \\
0\end{array}$} & $\begin{array}{l}\text { Categorias } \\
\text { Temáticas }\end{array}$ & Subcategorias \\
\hline & $\begin{array}{l}\text { Medicina como } \\
\text { técnica }\end{array}$ & $\begin{array}{l}\text { Naturalização das práticas } \\
\text { obstétricas }\end{array}$ \\
\hline & $\begin{array}{l}\text { Dinâmica } \\
\text { Teleoafetiva }\end{array}$ & $\begin{array}{l}\text { Mudança das práticas } \\
\text { obstétricas }\end{array}$ \\
\hline
\end{tabular}

Quadro 1 - Categorias emergentes da análise dos dados Fonte: Elaborado pela autora

Ressalto que, apesar de ter organizado meus diários de campo de acordo com os diferentes contextos nos quais as observações aconteceram, as categorias que emergiram da análise e interpretação dos dados ilustram atividades e práticas que aconteceram em vários desses espaços, uma vez que o contexto no qual uma prática se desdobra está para além de um espaço físico ou geográfico (T. R. Schatzki, 2005).

Por fim, em relação à codificação seletiva (Corbin \& Strauss, 1990), destaco que durante as etapas de análise e interpretação temática dos dados redigi "notas de análise", articulando os dados empíricos com ideias centrais e conceitos básicos do meu referencial teórico. Ao final desse processo, "o corpo" se revelou como minha categoria central, sendo as notas de análise muito importantes para a formulação e a revisão desse argumento (Glaser \& Strauss, 2006; Corbin \& Strauss, 1990).

\section{Apresentando e Discutindo os Resultados}

Conforme destacado, “o corpo" se revelou como o argumento central da análise dos dados, perpassando as demais categorias e subcategorias. Dessa forma, por meio de diferentes entendimentos acerca do arranjo material (T. R. Schatzki, 2002, 2012) "corpo da mulher" (enquanto paciente, gestante ou parturiente), há a naturalização, a reprodução das práticas obstétricas ou o esforço em prol da mudança dessas práticas.

Durante esta pesquisa, tive a oportunidade de acompanhar uma aula sobre humanização do parto, aula ministrada por um renomado obstetra aos residentes da 
maternidade do hospital universitário. O trecho a seguir, retirado do meu diário de campo, ilustra bem esses diferentes entendimentos acerca do corpo da mulher.

[...] a aula prosseguiu, o obstetra que a ministrava começou a tratar dos diferentes modelos/paradigmas da medicina, baseando-se no trabalho da antropóloga americana Davis-Floyd. Ele começou pelo paradigma tecnocrata. Segundo esse paradigma, há uma clara separação entre corpo X pessoa. A gestante é um corpo, e não uma pessoa. A gestação é tida como patologia, devendo ser solucionada o mais rápido possível. A gestante e o feto não podem morrer, mas intervenções, mesmo que clinicamente desnecessárias, podem e devem ser feitas; já que o objetivo é controlar o processo. Segundo o obstetra, o paradigma tecnocrático é uma herança da metafísica de Descartes, sendo o corpo tido como uma máquina. Consequentemente, o paciente é objetivado. Daí o nome “paciente”. O sujeito é o médico, ele é quem tem poder de agência, quem tem poder! Por outro lado, na lógica da medicina humanizada, a gestante não é chamada de paciente, mas sim de parturiente. Afinal, é ela quem está parindo. Dessa forma, a agência volta a ser da mulher. No paradigma tecnocrático e até difícil chamar o sujeito que procura o médico de outro nome, de outra “coisa”, já que o termo paciente está enraizado. Além disso, também é comum escutar a expressão "o obstetra fez o parto", como se o médico, e não a gestante, tivesse parido. Ou seja, o poder de agência é dado ao médico, e não à parturiente [...] (notas de campo, 27 de setembro de 2016).

Diante disso, percebe-se que o entendimento instrumental do corpo da mulher enquanto um objeto relaciona-se com a "medicina como técnica", sendo esse o entendimento dominante (apesar de não ser o único) em torno do qual o fazer obstétrico está organizado.

\section{Medicina Como Técnica: A Naturalização Das Práticas}


No Brasil, a formação do médico baseia-se no paradigma tecnocrático da medicina. Ao médico é ensinado reparar funções, supervalorizar a tecnologia (sendo a cesária a forma mais tecnológica e, portanto, a mais segura de parir) e seguir procedimentos padronizados (Georges \& Davis-Floyd, 2016). Dessa forma, esse é o contexto histórico e social (T. R. Schatzki, 2005) no qual as práticas obstétricas acontecem.

Em geral, os praticantes que são socializados nesse paradigma entendem a medicina enquanto uma técnica, incorporando microversões de um entendimento compartilhado (T. R. Schatzki, 2002, 2012) acerca do fazer médico e do corpo, naturalizando práticas médicas já legitimadas e tidas como certas, e reproduzindo um padrão de ação.

É nesse sentido que as práticas obstétricas se aproximam de uma (re)ação emergente e não refletida do indivíduo (que executa atividades rotinizadas que são aprendidas), uma ação guiada por um senso de propósito/finalidade que é socialmente construído, incorporado e aceito pelos praticantes (Nicolini, 2013; T. R. Schatzki, 2002).

Ao acompanhar a rotina da maternidade do hospital universitário, tive a oportunidade de presenciar momentos da socialização de alguns residentes em torno do fazer obstétrico. Apesar de ainda estarem no primeiro ano da residência em obstetrícia, alguns desses estudantes já reproduziam certos padrões de ação.

[...] por volta das 23 horas uma enfermeira entrou na sala dos plantonistas e anunciou a chegada de uma gestante: "temos uma gestante de 13 anos com bolsa rota". A residente do primeiro ano (R1) e os internos (graduandos do último ano de medicina) saíram imediatamente. $\mathrm{O}$ atendimento começou com a R1 pedindo para que a menina tirasse a calcinha no banheiro e, logo em seguida, deitasse na maca. O obstetra mais experiente, que também acompanhava o atendimento, não interviu, mas perguntou se a R1 já tinha olhado os papéis da menina. A R1 disse: “depois eu olho”. O obstetra se sentou e começou a olhar os papéis, checando todo o histórico do pré-natal. Enquanto o exame físico era feito pela residente e pelos internos, o obstetra falava em voz alta o que estava lendo: "Ela tem anemia. Ela está com 35 semanas de gestação. Ela já tomou a vacina pra fechar o pulmão do bebê”. Mais tarde, já no ambulatório 
onde o pré-natal é realizado, pude observar que outros obstetras mais experientes também começavam seu atendimento dessa forma: primeiro se conversa com a gestante, enquanto isso, o médico olha o histórico do pré-natal. Só então a paciente é examinada fisicamente. Pelo visto a residente estava perdendo a oportunidade de aprender. Lembro que na aula de humanização que assisti, o obstetra contava aos residentes que, segundo pesquisas, um médico deixa o paciente falar por apenas 18 segundos, tendo muita pressa em “colocar a mão na massa”. É o "hands-on" da medicina [...] (notas de campo, 13 de novembro de 2016).

Dessa forma, pude perceber que o entendimento de alguns praticantes acerca da medicina e do corpo era performado de modo quase normativo, guiando as ações desses profissionais como verdadeiros princípios, instruções, ou critérios de ação/decisão (T. R. Schatzki, 2002, 2012). Por exemplo, já na minha primeira observação, durante uma audiência pública sobre violência obstétrica, pude presenciar ditos que revelavam que o corpo da mulher muitas vezes é entendido pelos profissionais da saúde enquanto um objeto, enquanto um corpo defectivo e disfuncional que precisa de intervenções para ser capaz de dar a luz (Davis-Floyd \& John, 1998).

[...] durante a fala de algumas ativistas, de promotores públicos e de defensores dos direitos humanos e da mulher ficou claro que, atualmente, a episiotomia3 não é indicada como procedimento de rotina pelo Ministério da Saúde ou pela OMS. Todavia, apesar das falas anteriores, um dos obstetras que compunha a mesa rebateu, tentando explicar “didaticamente” (com uma cartolina e uma tesoura) a diferença entre episiotomia e laceração4. Ele rasgou um pedaço da cartolina, para, logo em

\footnotetext{
3 Incisão intencionalmente efetuada pelo obstetra na região do períneo (área muscular entre a vagina e o ânus) para ampliar o canal do parto. Quando feita sem indicação clínica e/ou sem o consentimento da mulher, a episiotomia é considerada violência obstétrica e mutilação genital (podendo acarretar disfunções sexuais e excretoras) (WHO, 2016).

4 Rompimento orgânico, ou seja, não intencional, da pele, da mucosa vaginal e até mesmo dos músculos perineais durante a passagem do bebê no parto vaginal. Por respeitar o desenho natural dos tecidos sua recuperação é mais rápida do que a de uma episiotomia. Além disso, a laceração não ocorre em todos os partos vaginais (WHO, 2016).
} 
seguida, cortar com a tesoura a parte que sobrou. Segundo ele "é muito mais fácil pro médico suturar um corte feito com bisturi do que uma laceração”. Quando a plateia pode participar do debate, uma outra ativista, que estava com uma folha em mãos, rasgou o papel e afirmou: “o corpo é meu, a vagina é minha! Se rasgar, o que nem sempre acontece quando o tempo do trabalho de parto é respeitado, vocês que aprendam a suturar... não sou eu quem tenho que me adaptar ao médico!” [...] (notas de campo, 23 de agosto de 2016).

[...] antes de a audiência começar, ativistas, promotores e defensores de direitos humanos/da mulher conversavam, ressaltando que a violência obstétrica era muito comum, cotidiana e corriqueira, sendo que muitas das mulheres sequer consideravam que estavam sendo violentadas, de tão arraigadas e tidas como certas eram certas práticas (a saber: proibição de a parturiente se movimentar durante o trabalho de parto, parto obrigatoriamente horizontal/na maca, amarrar as pernas da parturiente, episiotomia de rotina, dieta zero, proibição do acompanhante, uso rotineiro do fórceps). Entrei no papo e contei que um conhecido tinha um dos braços mais curto por conta do uso do fórceps; disse também que, pelos pra mim, sua mãe tinha sido praticamente violentada durante o parto. Uma ativista (que também é doula) comentou que o fórceps até pode ter indicação, mas que isso é raro; e que eu podia tirar o "praticamente" da minha frase. Antes de a conversa terminar, outras doulas contaram que o uso do fórceps acontece em muitos hospitais universitários, já que se entende que os residentes precisam aprender a usar esse "recurso", mesmo que não haja indicação clinica para tal [...] (notas de campo, 23 de agosto de 2016).

Durante outras observações, também pude perceber que alguns residentes, apesar de ainda estarem sendo socializados, demonstravam-se relutantes em absorver novas diretrizes 
(mesmo quando esse novo fazer era sugerido por obstetras mais experientes). O que também ilustra o efeito normativo do entendimento de alguns praticantes acerca da medicina e do corpo.

[...] o obstetra disse para a R1 não fazer o toque de hora em hora. Segundo ele, como a gestante não estava em trabalho de parto, a dilatação não aumentaria. Ele também explicou que o toque aumenta a chance de infecção, não sendo apenas uma causa de desconforto para gestante (o que para mim, já justifica o "não fazer”). O obstetra comentou que, segundo algumas pesquisas, ao passar seu trabalho de parto na maternidade de um hospital, uma mulher pode ser tocada por até 17 pessoas diferentes. Além disso, segundo ele, a gestante já deveria estar com infecção, já que nenhum outro sintoma justificava a bolsa rota com apenas 35 semanas. Apesar das recomendações, ouvi a R1 dizer que ela havia tocado a gestante, que continuava sem contração e com a mesma dilatação de 4 cm [...] (notas de campo, 14 de novembro de 2016).

Vale ressaltar que a residente simplesmente seguiu um dos procedimentos padronizados que havia aprendido durante sua formação: tocar a paciente de hora em hora, para assim acompanhar a evolução do trabalho de parto. Todavia, me chamou a atenção o fato de um residente do segundo ano (R2) não concordar com os procedimentos que estavam sendo adotadas pela R1.

[...] mais tarde, presenciei um R2 discordar dos toques em excesso: "eu não vou ficar tocando essa menina de hora em hora, ela não está tendo contração... além disso, ela é praticamente uma criança, tem 13 anos. Se eu tocar de 3 em 3 horas vou acompanhar do mesmo jeito a evolução dela. Pra que tocar de hora em hora?” [...] (notas de campo, 14 de novembro de 2016).

Ou seja, mesmo entre os residentes, profissionais que ainda estão em formação, sendo socializados, não há um consenso absoluto em relação ao que fazer e ao que não fazer. Afinal, 
conforme destaca T. R. Schatzki (2002), os indivíduos incorporam e carregam consigo diferentes microversões dos elementos que organizam as práticas (regras, entendimentos e teleoafetos), uma vez que cada praticante tem histórias de vida, habilidades e atitudes distintas. Mais uma vez, a prática social está para além de um padrão de ação, sendo melhor compreendida por meio de seu dinamismo e movimento (T. R. Schatzki, 2002, 2012).

\section{Dinâmica Teleoafetiva: A Mudança das Práticas}

Ainda em relação a nota de campo anterior, é interessante notar que o residente destacou o fato de a gestante ter apenas 13 anos. Ou seja, além desse residente ter um entendimento diferente em relação ao fazer obstétrico e ao corpo da gestante ("não vou ficar tocando [...] de hora em hora”), percebe-se que o mesmo foi “afetado” (Heidegger, 2005) pelo fato de a mesma ser menor de idade. Dessa forma, é possível afirmar que a teleoafetividade que organiza a prática - a complexa combinação de propósitos (telos), afetos, humores e emoções que os indivíduos sentem ao se engajarem em uma prática (T. R. Schatzki, 2002, 2012) - orientou o fazer obstétrico desse profissional.

Durante outros momentos da minha pesquisa, pude perceber que essa dinâmica teleoafetiva que organiza a prática também motivou outros profissionais da saúde a trabalharem de modo mais humanizado, contribuindo para a mudança do seu fazer obstétrico.

[...] minha mãe teve 5 filhos, todos por meio do parto natural. Eu cresci ouvindo histórias de parto, historias recheadas de afeto. Hoje em dia esse conhecimento não é mais passado de geração pra geração. As pessoas não sabem como foi o seu próprio parto. Muitas mulheres só passam a se interessar por esse tema quando pensam em engravidar ou já estão grávidas. Por conta disso, apesar de a minha formação na graduação e na residência ter sido tradicional, tecnicista e centrada no médico, como acontece com a grande maioria dos estudantes de medicina, esse modelo me incomodava [...] (notas de campo, 20 de setembro de 2016).

Além disso, outro relato desse mesmo obstetra me chamou a atenção: "[...] eu tive uma paciente chata, informada, que não aceitava tudo que eu falava, sempre rebatia... foi quando 
eu descobri que a mulher, a gestante, também tem desejo, preferências... enfim, ela é a protagonista do seu parto... e não eu, o médico! [...]" (notas de campo, 20 de setembro de 2016).

Segundo o relato de uma doula, outros obstetras da Grande Vitória passaram por experiências semelhantes, (des)construindo seu entendimento em relação à obstetrícia e ao corpo da mulher, assim como suas próprias práticas médicas.

[...] conversamos sobre como surgiu a parceria entre as doulas e a maternidade [de uma das cidades da Grande Vitória]. A doula me explicou que ela "doulou” uma amiga do obstetra que é diretor da maternidade, há uns 2 anos. "Na época ele estava descontruindo a cesária, já que ele era um obstetra que se autointitulada "cesarista", que praticava internações de rotina. Ele ainda não tinha mudado o chip, como ele mesmo fala. Ele fez o possível para oferecer para essa amiga uma experiência positiva e próxima do que ela queria para o seu parto. Ele desconstruiu muitas práticas. Não adianta, o médico sai da residência fazendo aquilo que ele aprendeu, fechado... Ele começou a frequentar o "Simpósio internacional de assistência ao parto”, que acontece todo ano em SP. Ele começou a entender que dentro da maternidade ele poderia fazer muita coisa. Porque o hospital tinha um histórico absurdo de violência obstétrica, pesado mesmo” [...] (notas de campo, 26 de agosto de 2016).

É dessa forma que novas dinâmicas teleoafetivas são incorporadas pelos praticantes, passando a (re)organizar a prática (do modelo tecnocrata dominante em direção a um fazer obstétrico mais humanizado).

Também é importante ressaltar que a dinâmica teleoafetiva que inicialmente levou os obstetras a "mudarem o chip" não significa que esses profissionais abriram mão da razão. Pelo contrário, conforme ilustra o trecho acima ("Ele começou a frequentar o 'Simpósio internacional de assistência ao parto', que acontece todo ano em SP”), é comum que gestantes e profissionais da saúde que se interessam pelo parto humanizado busquem evidências científicas e informações atualizadas para embasar suas escolhas e práticas. Uma das características dos EBP é justamente superar as várias dicotomias estabelecidas pelas 
teorias sociais clássicas (razão Vs. emoção, por exemplo), deslocando a ênfase para as relações entre as práticas cotidianas. Afinal, os fenômenos sociais não são independentes, mas mutuamente constituídos, havendo uma relação recursiva, reflexiva entre eles. Assim, tais “contradições" enfatizam as conexões entre os elementos que compõem a práticas, e não a dicotomia, a necessidade de se escolher entre um ou outro.

Durante as conversas que tive com meu informante também pude vivenciar essa busca por embasamento científico, já que sempre que nos encontramos volto para casa com livros, teses e referências de artigos. Aliás, também foi em um congresso acadêmico que esse obstetra conheceu o modelo europeu de atenção ao parto e passou a se interessar pela humanização.

[...] eu era recém-formado, ainda não tinha nem feito mestrado, mas gostava de pesquisar... fiz um levantamento sobre o uso do fórceps nos partos do ES e mandei para um congresso na Europa. Fui aprovado! Eu fui como jovem pesquisador... lá eu conheci o modelo europeu de atenção ao parto. Engraçado, né?! O fórceps me levou para o parto humanizado! [...] (notas de campo, 20 de setembro de 2016).

As gestantes que optam pelo parto humanizado também buscam se informar. Durante esta pesquisa tive a oportunidade de acompanhar um grupo de gestantes, pais e doulas que se reúnem em uma universidade federal, compartilhando suas vivências com outras mulheres que também desejam passar pela experiência do parto humanizado e estão buscando informação. O relato a seguir ilustra que mulheres bem informadas se sentem mais seguras em relação ao seu próprio corpo, entendendo que são capazes de parir de modo natural.

[...] apesar de tudo conspirar em prol de mais um parto cesariano, nós resolvemos nos informar, ter uma equipe preparada ao nosso lado e focar nos casos de parto natural para bebês pélvicos (quando o bebê está sentado) que deram certo. A cesária é uma cirurgia, se fosse necessário, se houvesse um risco para o bebê, ok. Mas pra mim, o simples fato do meu bebê estar sentado não era um risco real. Eu poderia até fazer uma cesária, mas por outros motivos, por eventuais complicações durante o parto, por exemplo. Eu queria sentir o que minha mãe sentiu quando eu nasci, desde 
as transformações do meu corpo durante os meses de gestação, até as sensações do trabalho de parto, o parto em si e o pós-parto. Mas sem o desfecho da cesariana. Meu parto foi tão natural que eu não tive laceração; o que costuma ser uma das preocupações do parto pélvico [...] (notas de campo, 29 de agosto de 2016).

É interessante ressaltar que o plano dessa mulher era ter um parto natural hospitalar. Todavia, ela entrou em trabalho de parto em casa, sem nenhum tipo de intervenção obstétrica. Ou seja, o parto simplesmente aconteceu, naturalmente. Afinal, parir é natural, sendo o corpo da mulher capaz de dar à luz!

Diante disso, o entendimento de que não é possível desassociar a mulher do seu próprio corpo - “corpo-pessoa” (Flores-Pereira, 2010) - pode ser relacionado com práticas obstétricas mais humanizadas, contribuindo para a mudança incremental do fazer obstétrico.

A representação de pessoa que predomina nos Estudos Organizacionais se refere a um sujeito dividido entre corpo e mente. Sob esse ponto de vista, o corpo é apenas mais um objeto que a pessoa detém, sendo comumente representado de forma instrumental; ou seja, enquanto um instrumento/objeto que serve às pessoas - que não são um corpo, e sim uma mente (Flores-Pereira, 2010).

É essa base filosófica cartesiana que sustenta a percepção moderna e instrumental do homem enquanto um ser capaz de manusear, manipular, controlar e subordinar toda a natureza (o que inclui inclusive os corpos) (Henriques, 2014). Foi essa a base filosófica que influenciou nossa sociedade, nossa forma de fazer ciência e, até mesmo, muitas das práticas médicas/obstétricas que hoje ainda estão em vigor. Dessa forma, a ideia de "corpo-pessoa" rompe com mais uma das dicotomias das teorias sociais: o dualismo que separa sujeito (mente) e objeto (corpo) em polos diametralmente opostos. Afinal, padrões corporais e mentais são componentes necessários e inerentes das práticas e, portanto, da vida social (Reckwitz, 2002; T. R. Schatzki, 2002).

\section{Considerações Finais}

O objetivo desta pesquisa é analisar como a organização do fazer obstétrico motiva os praticantes a optar pelo parto humanizado, contribuindo, assim, para a mudança das 
práticas obstétricas. O “corpo” se revelou como o argumento central da análise dos dados, relacionando-se com as demais categorias e subcategorias. Dessa forma, por meio de diferentes entendimentos acerca do arranjo material “corpo da mulher” (enquanto paciente, gestante ou parturiente), há a naturalização, a reprodução das práticas obstétricas ou o esforço em prol da mudança dessas práticas.

$\mathrm{O}$ entendimento instrumental do corpo enquanto um objeto relaciona-se com a "medicina como técnica”, com a naturalização de práticas médicas legitimadas e tidas como certas. Muitas vezes, esse entendimento é performado pelos praticantes como uma regra, tendo um efeito normativo, guiando as ações de mulheres e profissionais da saúde, que tendem a reproduzir um padrão de ação (a cesária, por exemplo).

Por outro lado, não há um consenso absoluto em relação ao que (não) fazer. Afinal, os indivíduos carregam diferentes microversões dos elementos regras, entendimentos e teleoafetos que organizam as práticas. Dessa forma, a dinâmica teleoafetiva que organiza o fazer obstétrico (a violência obstétrica, por exemplo) pode motivar mulheres e profissionais da saúde a optarem por um parto mais humanizado; (des)construindo seu entendimento em relação à obstetrícia e ao corpo da mulher, contribuindo para a mudança das suas próprias práticas. Afinal, o processo de "dissolução-emergência" das práticas acontece quando novos meios e fins (ou seja, novas teleoafetividades) passam a organizar uma prática, o que também pode transformar os entendimentos práticos dos indivíduos que performam essas atividades, já que a motivação e o propósito da ação são alterados (T. Schatzki, 2013).

Isso reforça a ideia de que a prática social vai além da repetição de ações rotinizadas, de um padrão de ação, abarcando atividades que estão em constante transformação; sendo a agência humana a fonte primária da mudança de qualquer nexo de práticas e arranjos (T. R. Schatzki, 2002).

Além disso, apesar de as expressões paciente, gestante e parturiente soarem, pelo menos aparentemente, como sinônimos, seu uso ocorre em contextos bem distintos. Quando a mulher é compreendida pelos profissionais da saúde como paciente, seu corpo é tido enquanto um objeto e a gravidez como um problema a ser resolvido. Por outro lado, quando a mulher é compreendida como gestante ou parturiente, seu corpo passa a ser um "corpo-pessoa"; não sendo possível desassociar essa mulher desse corpo. Segundo FloresPereira (2010, p. 422), “[...] a pessoa não é aquela que se encontra dentro de um corpo (uma mente, uma razão, uma subjetividade). Ela ‘é' o próprio corpo [...]”. Consequentemente, a gravidez deixa de ser um problema, tornando-se um processo natural e fisiológico que deve 
ser respeitado, e não solucionado o mais rápido possível (por meio de uma cesária eletiva ou de uma episiotomia, por exemplo).

Dessa forma, os ditos (as expressões paciente, gestante e parturiente, por exemplo) e não somente os feitos - são facetas das práticas, revelando os diferentes entendimentos dos praticantes acerca das práticas e dos arranjos que as suportam. Afinal, a realidade social é complexa e múltipla, havendo uma variedade de ordens, lógicas e discursos que, assim como as práticas, podem se sobrepor e coexistir.

Além disso, a "referência", o "para que serve" do corpo da mulher enquanto um arranjo material que compõem a prática obstétrica se revela de distintas formas: corpo objeto ou corpo-pessoa. Consequentemente, dependendo dessa referencia dos corpos, entende-se que a mulher é capaz (corpo-pessoa) ou incapaz (corpo objeto) de dar à luz. Isso faz com que a decisão pelo tipo de parto (natural ou cirúrgico) vá além de uma escolha meramente racional, não sendo determinada somente por fatores clínicos, abarcando toda uma dinâmica teleoafetiva que organiza o fazer obstétrico enquanto uma prática social qualquer.

Este trabalho contribui com o campo ao analisar como a mobilização das práticas se altera ao longo do tempo; o que nos ajuda a apreender não somente o dinamismo das práticas obstétricas, mas de toda e qualquer prática. Além disso, o estudo da obstetrícia revela a centralidade do arranjo material "corpo" na performance dessa prática social. Sem os outros arranjos (sem os corpos do acompanhante, do obstetra, da doula, ou sem a maternidade, por exemplo) a prática continuaria a se desdobrar. Todavia, o mesmo não aconteceria sem o corpo da mulher. Afinal, é esse corpo que entra em trabalho de parto, que dá a luz e que, infelizmente, sofre violência obstétrica; enfim é esse o veículo que transporta as práticas obstétricas (Reckwitz, 2002; T. R. Schatzki, 2001).

Uma das limitações desta pesquisa é o fato dos dados empíricos coletados estarem mais voltados para os agentes que realizam a assistência ao parto (uma vez que acompanhei majoritariamente a rotina de doulas e obstetras), assim como para gestantes que optaram pelo parto normal. Todavia, sendo esta uma pesquisa ainda em andamento, destaco que a observação sistemática dos demais sujeitos (mulheres que optam pela cesária, por exemplo) que também performam o fazer obstétrico já está sendo realizada. Afinal, a realidade social é múltipla, havendo uma variedade de lógicas e discursos que podem coexistir (Mol, 2002; Mol \& Law, 2002; T. R. Schatzki, 2002); não sendo meu objetivo silenciar esses praticantes.

Por fim, acredito que após a incorporação desses novos dados à análise e interpretação temática novas categorias/subcategorias irão emergir, revelando que 
"naturalização/reprodução" e "mudança" das práticas são polos de um continuum e não simplesmente uma dicotomia. Afinal, a vida social é um acontecimento sempre inacabado, em constante construção (ongoing routine) (T. R. Schatzki, 2006; Nicolini, 2013; Czarniawska, 2013); sendo a mudança do fazer obstétrico a (re)construção do emaranhado de práticas (o que inclui a (re)organização dos elementos entendimentos, regras e teleoafetos) que dá vida à esse fenômeno social. 


\section{Referências}

Angrosimo, M. (2007). Doing ethnographic and observational research. London, Thousand Oaks, New Delhi: Sage Publications.

Betran, A. P., Torloni, M. R., Zhang, J. J., \& Gülmezoglu, A. M. (2015). Who statement on caesarean section rates. Bjog: An International Journal Of Obstetrics \& Gynaecology, $123,667-670$.

Boas, F. (2004). Antropologia Cultural. Rio de Janeiro: Jorge Zahar.

Bruni, A., \& Rizzi, C. (2013). Looking For Data In Diabetes Healthcare: Patient 2.0 And The Re-Engineering Of Clinical Encounters. Science \& Technology Studies, 26(1), 29-43.

Carter, C., Clegg, S. R., \& Kornberger, M. (2010). Um Livro Bom, Pequeno E Acessível Sobre Estratégia. Bookman.

Corbin. J., \& Strauss, A. (1990). Grounded Theory Research: Procedures, Canons, And Evaluative Criteria. Qualitative Sociology, 13(1), 3-21.

Czarniawska, B. (2013). Organizations As Obstacles To Organizing. In: Robichaud, D., \& Cooren, F. (Eds). Organization And Organizing. Routledge.

Davis-Floyd, R., \& John, G. S. (1998). From doctor to healer: The transformative journey. Rutgers University Press.

Domingues, R. M. S. M., Dias, M. A. B., Nakamura-Pereira, M., Torres, J. A., D’orsi, E., Pereira, A. P. ... Leal, M. D. C. (2014). Process of decision-making regarding the mode of birth in Brazil: from the initial preference of women to the final mode of birth. Cadernos de Saúde Pública, 30(Supl. 1), S101-S116.

Feldman, M. S. \& Orlikowski, W. J. (2011). Theorizing practice and practicing. Theory. Organization Science, 22(5), 1240-1253.

Flores-Pereira, M. T. (2010). Body, person and organizations. Organizações \& Sociedade, 17(54), 417-438.

Fundação Oswaldo Cruz. (2016). Nascer no Brasil: inquérito nacional sobre parto e 
nascimento. Rio de Janeiro. Recuperado de http://www6.ensp.fiocruz.br/nascerbrasil/metodologia

Georges, E., \& Davis-Floyd, R. (2016). Humanistic obstetrics in Brazil. In L. Manderson, E. Cartwright, \& A. Hardon. (Eds.). The routledge handbook of medical anthropology. Routledge.

Gherardi S., \& Perrotta M. (2011). Egg dates sperm: A tale of a practice change and its stabilization, Organization, 18(5), 595-614.

Glaser, B. G., \& Strauss, A. (2006). The discovery of grounded theory: Strategy for qualitative research. New Burnswick, London: Aldine.

Heidegger, M (2005). Ser e tempo. Parte I. 14. ed. Petrópolis, RJ: Vozes.

Henriques, R. P. (2014). Tecnologia, objetividade e superação da metafísica. 1. ed. Vitória: EDUFES.

Júlio, A. C. (2016). Produzindo o desfile de uma escola de samba: contribuições da epistemologia de Schatzki. RIGS: Revista Interdisciplinar de Gestão Social, 5(3), 145161.

Malinowski, B. (1978). Argonautas do Pacífico Ocidental. São Paulo: Abril Cultural.

Mantere. S. (2005). Strategic practices as enablers and disablers of championing activity, Strategic Organization, 3(2), 157-184.

Marcus, G. E. (1995). Ethnography in/of the world system: The emergence of multi-sited ethnography. Annu. Rev. Anthropol, 24, 95-117.

Mol, A. (2002). The body multiple: Ontology in medical practice. Durham, NC: Duke University Press.

Mol, A., \& Law, J. (2002). Complexities: An introduction. In J. Law, \& A. Mol. (Eds.). Complexities: Social studies of knowledge practices, science \& cultural theory. Durham, NC: Duke University Press, 1-22.

Nicolini, D. (2013). Practice theory, work, \& organization: An introduction. Oxford: Oxford 
University Press.

Patah, L. E. M., \& Malik, A. M. (2011). Modelos de assistência ao parto e taxa de cesa' rea em diferentes pai' ses. Revista de Sau'de Pu’blica, 45(1), 185-194.

Reckwitz, A. (2002). Toward a theory of social practices: A development in culturalist theorizing. European Journal of Social Theory, 5(2), 243-263.

Reckwitz, A. (2012). Affective spaces: A praxeological outlook. Rethinking History: The Journal Of Theory And Practice, 16(2), 241-258.

Rosen, M. (1991). Coming to terms with the field: Understanding and doing organizational ethnography. Journal Of Management Studies, (28)1, 1-24.

Ryan, G. W., \& Bernard, R. (2003). Techniques to identify themes. Field Methods, (15)1, 85109.

Santos, L. L. S., \& Silveira, R. A. (2015). Por uma epistemologia das práticas organizacionais: A contribuição de Theodore Schatzki. Organizações \& Sociedade, 22(72), 79-98.

Schatzki, T. R. (2001). Subject, body, place. Annals of the Association of American Geographers, 91(4), 698-702.

Schatzki, T. R. (2002). The site of the social: A philosophical account of the constitution of social life and change. Pennsylvania: Pennsylvania State University.

Schatzki, T. R. (2005). The sites of organizations. Organization Studies. 26(3), 465-484.

Schatzki, T. R. (2006). On organizations as they happen. Organization Studies, 27(12), $1863-1873$.

Schatzki, T. R. (2012). A primer on practices: Theory and research. In J. Higgs, R. Barnett, S. Billett, M. Hutchings, \& F. Trede. (Eds). Practice-based education: Perspectives and strategies. Rotterdam, The Netherlands: Sense Publishers.

Schatzki, T. (2013). The edge of change: On the emergence, persistence, and dissolution of practices. In E. Shove, \& N. Spurling. (Eds). Sustainable practices: social theory and climate change. London, Routledge. 
Scott, W. R. (1972). Field methods in the study or organizations. In J. G. March (Ed). Handbook of organizations. Chicago: Rand Mcnally \& Company.

Spradley, J. P. (1979). The ethnographic interview. Belmont, Ca: Wadsworth Group \& Thomson Learning.

Universidade de São Paulo. (2016). Curso de obstetrícia da escola de artes, ciências e humanidades: Perguntas frequentes. São Paulo. Recuperado de http://www.each.usp.br/obstetricia/perguntas.htm

World Health Organization. (2016). Maternal, newborn, child and adolescent health. Recuperado de http://www.who.int/maternal_child_adolescent/en/

Wiegers, T. A., Van Der Zee, J., Kerssens, J. J., \& Keirse, M. J. N. C. (1998). Home birth or short-stay hospital birth in a low risk population in the Netherlands. Social Science \& Medicine, 46(11), 1505-1511.

Yanow, D. (2012). Organizational ethnography between toolbox and world-making. Journal of Organizational Ethnography, 1(1), 31-42. 